Article

\title{
Can Climate Change Negotiations Succeed?
}

Jon Hovi ${ }^{1,2}$, Tora Skodvin ${ }^{1}$ and Stine Aakre ${ }^{2}$

${ }^{1}$ Department of Political Science, University of Oslo, P.O. Box 1097 Blindern, 0317 Oslo, Norway;

E-Mails: jon.hovi@stv.uio.no (J.H.), tora.skodvin@stv.uio.no (T.S.); Tel.: +47 22855192 (J.H.);

Fax: +47 22854411 (J.H.)

${ }^{2}$ Center for International Climate and Environmental Research-Oslo (CICERO), P.O. Box 1129 Blindern, 0318 Oslo, Norway; E-Mail: stine.aakre@cicero.uio.no (S.A.)

\section{How to Cite this Article}

Hovi, J., Skodvin, T., \& Aakre, S. (2013). Can Climate Change Negotiations Succeed? Politics and Governance, 1(2), 138-150.

\section{Acknowledgement}

This Article was published by Librello, Politics and Governance's former publisher.

\section{About the Journal}

Politics and Governance is an innovative new offering to the world of online publishing in the Political Sciences. An internationally peer-reviewed open access journal, Politics and Governance publishes significant, cutting-edge and multidisciplinary research drawn from all areas of Political Science.

www.cogitatiopress.com/politicsandgovernance

\section{Editors-in-Chief}

Professor Andrej J. Zwitter, Faculty of Law, University of Groningen, The Netherlands

Professor Amelia Hadfield, Department of Psychology, Politics and Sociology, Canterbury Christ Church University, UK

\section{Managing Editor}

Mr. António Vieira, Politics and Governance, Cogitatio Press, Portugal 


\title{
Can Climate Change Negotiations Succeed?
}

\author{
Jon Hovi ${ }^{1,2, *}$, Tora Skodvin ${ }^{1}$ and Stine Aakre ${ }^{2}$ \\ ${ }^{1}$ Department of Political Science, University of Oslo, P.O. Box 1097 Blindern, 0317 Oslo, Norway; \\ E-Mails: jon.hovi@stv.uio.no (J.H.), tora.skodvin@stv.uio.no (T.S.); Tel.: +47 22855192 (J.H.); \\ Fax: +4722854411 (J.H.) \\ ${ }^{2}$ Center for International Climate and Environmental Research-Oslo (CICERO), P.O. Box 1129 Blindern, \\ 0318 Oslo, Norway; E-Mail: stine.aakre@cicero.uio.no (S.A.) \\ * Corresponding author
}

Submitted: 1 June 2013 | In revised form: 5 September 2013 | Accepted: 6 September 2013 |

Published: 20 September 2013

\begin{abstract}
More than two decades of climate change negotiations have produced a series of global climate agreements, such as the Kyoto Protocol and the Copenhagen Accords, but have nevertheless made very limited progress in curbing global emissions of greenhouse gases. This paper considers whether negotiations can succeed in reaching an agreement that effectively addresses the climate change problem. To be effective, a climate agreement must cause substantial emissions reductions either directly (in the agreement's own lifetime) or indirectly (by paving the way for a future agreement that causes substantial emissions reductions directly). To reduce global emissions substantially, an agreement must satisfy three conditions. Firstly, participation must be both comprehensive and stable. Secondly, participating countries must accept deep commitments. Finally, the agreement must obtain high compliance rates. We argue that three types of enforcement will be crucial to fulfilling these three conditions: (1) incentives for countries to ratify with deep commitments, (2) incentives for countries that have ratified with deep commitments to abstain from withdrawal, and (3) incentives for countries having ratified with deep commitments to comply with them. Based on assessing the constraints that characterize the climate change negotiations, we contend that adopting such three-fold potent enforcement will likely be politically infeasible, not only within the United Nations Framework Convention on Climate Change, but also in the framework of a more gradual approach. Therefore, one should not expect climate change negotiations to succeed in producing an effective future agreement-either directly or indirectly.
\end{abstract}

Keywords: climate change negotiations; compliance; cooperation; enforcement; participation; political feasibility 


\section{Introduction}

More than 20 years of climate negotiations have produced a series of global climate agreements. Examples include the United Nations Framework Convention on Climate Change (UNFCCC, 1992), the Kyoto Protocol (Kyoto 1, 1997), the Marrakesh Accords (2001), the Bali Road Map (2007), the Copenhagen Accord (2009), and the Durban Platform (2012), to mention only the most important ones.

Of course, these agreements differ significantly. Only the Kyoto Protocol and the Copenhagen Accord are associated with specific commitments concerning emissions reductions or limitations. Whereas Kyoto includes jointly determined and legally binding targets for such reductions or limitations, the Copenhagen Accord entails only unilaterally determined and nonbinding targets that are not even part of the text. The Marrakesh Accords are largely a companion agreement to Kyoto, with specifications concerning the compliance system and the flexibility mechanisms (emissions trading, joint implementation, and the green development mechanism). Finally, the Bali Road Map and the Durban Platform essentially provide aims and guidance for further negotiations.

The many agreements over more than two decades notwithstanding, the climate negotiations have made very little progress in terms of curbing global emissions of greenhouse gases (GHGs). According to the Netherlands Environmental Assessment Agency, global $\mathrm{CO}_{2}$ emissions in 2010 exceeded the 2000 level by $33 \%$ and the 1990 level by 45\% [1]. Hence, if anything, the growth in global emissions is accelerating.

What explains this striking lack of progress in the climate negotiations? Considering that the delegations to the UNFCCC Conferences of the Parties consist of highly skilled experts and diplomats, it is unlikely that insufficient knowledge of the problem at hand or lack of innovative proposals for an effective design of the international climate regime explains the lack of progress. It seems far more promising to seek the explanation at the structural level, as this paper does. In particular, we consider whether the constraints faced by the negotiators are so severe that it is unrealistic to expect that they can be overcome. In other words, we consider whether the global climate change negotiations can succeed [2].

Providing a meaningful answer to this research question presupposes a clear definition of what success means. It is far from obvious what such a definition should look like; indeed, several conceivable success criteria exist.

A first possible criterion is simply to require that the negotiators reach an agreement (regardless of its contents). Any one of the aforementioned agreements (as well as any other conceivable agreement) would obviously count as a success based on this first criterion. Hence, this criterion is too weak to be interesting.

A second possible criterion is that to count as a success, the agreement negotiators reach must include commitments for emissions reductions or limitations by at least some member countries. In terms of this second criterion, the Kyoto Protocol would count as a success, because it required 36 countries to reduce their annual emissions in the period 2008-2012 by $5.2 \%$ on average, compared to 1990 levels.

A third possible criterion is that the agreement's design must make ratification politically feasible in all major countries. According to this criterion, Kyoto cannot be counted as a success, because it was not ratified by the United States, the world's largest emitter of GHGs at the time of the Kyoto meeting. Indeed, President Clinton did not even submit the treaty to the Senate, presumably because it had no chance of obtaining the Senate's consent [3].

Finally, a fourth possible success criterion is that the agreement must be effective. An agreement is here deemed effective if it causes substantial emissions reductions either directly (in the agreement's own lifetime) or indirectly (by paving the way for a future agreement that causes substantial emissions reductions directly) [4]. In this article, we use this fourth success criterion. We realize that the criterion is not particularly precise; however, for our purposes it is not of great importance whether reducing emissions "substantially" means meeting the $2^{\circ} \mathrm{C}$ target (see the next section), meeting a $3^{\circ} \mathrm{C}$ target, or meeting some other precise target. The point is that, according to this criterion, a successful agreement must be either directly or indirectly effective. Obviously and as already noted, the aforementioned agreements do not even come close to being directly effective-individually or collectively. Moreover, they do not include institutional arrangements that make them indirectly effective either. If anything, current UNFCCC rules hinder rather than spur substantial global emissions reductions. For example, the 1995 Berlin Mandate introduced the principle that UNFCCC parties should "protect the climate system in accordance with their common but differentiated responsibilities and respective capabilities" [5]. This principle places the responsibility for undertaking emissions reductions squarely on the Annex I countries, which are currently responsible for only about $40 \%$ of global emissions.

We proceed as follows: in Section 2 we point out some reasons why the climate change problem is so difficult to solve. In Section 3 we consider the prospects for a directly effective climate agreement. In particular, we maintain that the key to a directly effective climate agreement is potent enforcement, and contend that potent enforcement is politically infeasible in the global UNFCCC framework. In Section 4 we address the prospects for an indirectly effective agreement, arguing that obtaining substantial global emissions reductions through a more gradual (or clublike) approach is also politically infeasible. Finally, in Section 5 we conclude. 


\section{Why Is the Climate Change Problem so Difficult to Solve?}

The climate change problem is complex in both scientific and political terms. Over the last two and a half decades, much energy has been invested in assessing its scientific aspects. The Intergovernmental Panel on Climate Change (IPCC) was established in 1988 , and has since published regular assessments of state-of-the-art knowledge on the climate system's physical aspects, assessments of countries' socioeconomic vulnerability to climate change, and assessments of adaptation and mitigation options. While this process has met criticism (e.g., [6]), policymakers seem largely to have accepted the IPCC's conclusion that anthropogenic emissions of GHGs are associated with a risk of human-induced climate change. In 2009, for instance, climate negotiators at the Copenhagen meeting (the 15th Conference of the Parties to the Climate Convention, COP-15) recognized "the scientific view that the increase in global temperature should be below 2 degrees Celsius" (Copenhagen Accord, paragraph 1). Policymakers further agreed that "deep cuts in global emissions are required according to science" and that they would "take action to meet this objective [the $2^{\circ} \mathrm{C}$ target, authors]" (Copenhagen Accord, paragraph 2) [7]. So far, however, policymakers have been unable to agree on how to achieve the necessary emissions reductions to meet this target.

Several factors contribute to making the climate change problem difficult to solve. Firstly, climate mitigation resembles a global public good. Thus, no country can be excluded from enjoying the benefits of climate mitigation, even if it fails to contribute to such mitigation. This aspect of global public goods means that most of the benefits from a country's own mitigation efforts go to others. Indeed, a major motivation for a country to participate in climate cooperation is to ensure that the net costs of its own mitigation efforts are outweighed by the benefits it derives from mitigation efforts in other countries. Moreover, the contributions of most individual countries to climate mitigation, especially those of small countries, matter little for the global climate. For example, even if Norway were to eliminate all of its emissions of GHGs, global emissions would become only about $0.15 \%$ smaller than if Norway were to continue business as usual. The effect on global warming would thus hardly be noticeable.

Secondly, a significant time lag exists between the costs of implementing GHG emissions reductions and the benefits of climate mitigation effects. While costs are incurred immediately, it may take decades until a measure's benefits take effect [8]. In contrast, policymakers typically have a much shorter time perspective and tend to favor measures associated with immediate benefits and delayed costs. Policymakers will always have good reasons for delaying action on long-term problems; in particular, they will often want to prioritize more immediate societal challenges (e.g., the financial crisis, the debt crisis, health care, seniors' welfare, etc.). Furthermore, depending on how long climate benefits take to materialize, not all the people carrying the costs will enjoy the benefits. This disparity might cause policymakers to delay action.

These two factors imply that the climate change problem involves a free-rider problem. Actors have strong incentives to enjoy the benefits of other actors' mitigation efforts while not contributing to mitigation themselves. Climate mitigation will thus likely be provided only in suboptimal quantities.

Thirdly, GHG emissions reductions on the scale necessary to solve the climate change problem are very costly because almost all economic activities are associated with GHG emissions. Of course, some climate measures may be economically beneficial in their own right. For instance, investments in renewable energy and energy efficiency may create new jobs, reduce energy costs, and increase energy security. Therefore, many countries have adopted climate measures even in the absence of an international agreement. These types of measures, however, are insufficient to generate the scope of emissions reductions required for effective climate mitigation. Moreover, which climate measures are economically beneficial is strongly linked to country-specific economic conditions. Thus, an effective international agreement must require countries to implement emissions reductions beyond the scope of measures that are beneficial in their own right within the framework of each country's economy. It must also include costly reduction measures even for the most carbon-intensive sectors. At that point, conflicts over burden sharing set in and incentives to free ride take effect. Climate measures that are beneficial in their own right, therefore, do little to help overcome the barriers to global collective action. On the contrary, they may arguably contribute to legitimize free riding.

The current energy and climate policy debate in the EU illustrates the continuing significance of emissions reduction costs. The EU has pursued ambitious climate policies for more than a decade and has had an operative Emissions Trading Scheme (ETS) since 2005. Nevertheless, the costs associated with ambitious climate policies are still a key concern in the climate and energy policy debate. In May 2013, the EU heads of state declared that "EU policy must ensure 'competitive' energy prices" and recognized a need to diversify the EU's "indigenous energy resources" to include not only renewable energies but also coal, nuclear power, and shale gas. German member of the European Parliament, Holger Krahmer responded, "for the first time, rising energy costs and the declining competitiveness of the European economy will be rated higher than obviously unenforceable global climate change ambitions" [9]. Moreover, the director of BUSINESSEUROPE blamed "the cost of climate policies-such as the ETS, renewable energy support schemes, and the structure of electricity markets-for the bloc's flagging economy" [9]. 
The costs associated with GHG emissions reductions imply that the free-rider problem is even more severe for the climate problem than for other environmental problems. The point is well illustrated by Canada's Environment Minister, Peter Kent, who justified Canada's withdrawal from the Kyoto Protocol in the following way: "the transfer of $\$ 14$ billion from Canadian taxpayers to other countries-the equivalent of $\$ 1,600$ from every Canadian family - with no impact on emissions or the environment. That's the Kyoto cost to Canadians" [10]. Given that actors will likely implement the least costly measures first, moreover, the cost of new measures will tend to increase, which reinforces incentives to free ride.

Fourth, domestic politics tend to give the upper hand to opponents of implementing climate mitigation measures. Whatever few benefits such measures provide to domestic constituents are long-term, vague, and highly dispersed. They thus give little incentive for political action. In contrast, costs are often nearterm, salient, and highly concentrated. They are thus more likely to result in efforts to influence policymakers (e.g., [11]).

Finally, a number of strong asymmetries further aggravate the climate change problem. Countries vary greatly concerning their historical responsibility for causing the problem, concerning their sensitivity to climate change, and concerning their capacities for mitigation and adaptation. These asymmetries partly explain why debates about justice or equity tend to be contaminated by "self-serving bias", that is, countries tend to invoke distributional principles that favor themselves. These asymmetries make difficult a consensus on what a just climate agreement would look like, and make justifying free-riding behavior easy.

Given all these factors, the Kyoto Protocol (Kyoto 1) was unsurprisingly associated with several types of free riding [12]: firstly, the United States did not ratify. Secondly, Canada ratified but subsequently withdrew from the agreement. Thirdly, "hot air" countries such as Belarus, Russia, and Ukraine participated with rather lenient emissions control commitments. Fourthly, developing countries (including countries such as China and India) participated without emissions control commitments. Finally, some countries may have participated without complying (fully) with their commitments. Whether some did (and if so, which ones) is not known at the time of writing. Kyoto 1 , moreover, imposed relatively small emission cuts on Annex I countries [13] (and none at all on other member countries). A future agreement with a higher ambition level would give actors even stronger incentives to free ride.

\section{The Feasibility of a Directly Effective Climate Agreement}

To be effective (in the sense outlined in Section 1), a new climate agreement must cause substantial global emissions reductions either directly or indirectly. Here we focus on the prospects for a directly effective agreement, while we consider the prospects for an indirectly effective agreement in Section 5.

\subsection{Conditions for a Directly Effective Climate Agreement}

To cause substantial global emissions reductions directly, an agreement must satisfy three main criteria. Firstly, participation must be both comprehensive and stable. While it may be difficult to specify exactly what counts as comprehensive, the number of participating countries is clearly less important than the participating countries' share of global GHG emissions. Whereas emissions in tiny countries such as Lichtenstein, San Marino, and Andorra are largely inconsequential for global warming, the G20 countries are responsible for approximately $80 \%$ of global emissions [14]. Thus, a new climate agreement ratified by all G20 countries would go far towards satisfying the comprehensiveness condition. However, even an agreement with comprehensive membership may not be very helpful unless the membership is also stable: the ratifiers must remain members throughout the agreement's lifetime. For example, the Kyoto Protocol was unstable in the sense that Canada withdrew in December 2011. Moreover, other countries participating in Kyoto 1 have followed Canada's example by making clear they will not participate in Kyoto 2.

Secondly, participating countries must accept deep commitments, that is, they must promise substantial emissions reductions. It is well known that some international environmental agreements (IEAs) are shallow, in that participants promise little more than business as usual $[15,16]$. In contrast, to be effective, a climate agreement must require participants to deviate extensively from business-as-usual emissions trajectories. Because almost all economic activity entails GHG emissions, such deviations will likely be very costly (e.g., [17]).

Finally, the agreement must display high compliance rates, that is, participating countries must actually implement their deep commitments. The more costly such implementation, the less likely that high compliance rates will emerge (other things being equal).

Given the strong incentives for free riding (see Section 2), it is unlikely that all of these three conditions can be fulfilled in a new climate agreement unless that agreement includes potent enforcement measures.

\subsection{The Key to an Effective Agreement: Potent Enforcement}

While "enforcement" is often defined in terms of negative incentives ("sticks"), we here follow Breitmeier et al. [18], who broaden the enforcement concept to include positive incentives ("carrots") as well. We thus 
define "enforcement" as the promise, threat, or actual use of positive or negative incentives to induce countries to behave (or abstain from behaving) in a certain way [19].

An effective climate agreement will require three types of enforcement: (1) incentives for countries to ratify with deep commitments, (2) incentives for ratifiers with deep commitments to abstain from withdrawal, and (3) incentives for ratifiers with deep commitments to comply with them.

Including measures for these three types of enforcement is not enough, however. The enforcement measures must also be potent, that is, they must be able to actually modify the behavior of would-be free riders. Such ability requires that enforcement measures be both credible and sufficiently big. Sticks are sufficiently big if would-be free riders would rather refrain from free riding and go unpunished than free ride and suffer punishment. Carrots are sufficiently big if wouldbe free riders would rather refrain from free riding and receive the promised reward than free ride and not receive it.

Stick measures are credible if other participants (or an enforcement institution erected and empowered by participants) can be expected to actually use them against free-riding countries. Similarly, carrot measures are credible if other participants (or an enforcement institution) can be expected to actually provide them to countries that do not free ride.

We emphasize that including one or two types of enforcement, but not the third, will likely be of limited help. For example, an agreement that includes potent type 2 and type 3 incentives, but not potent type 1 incentives, would likely face great difficulties in persuading all major countries to ratify (or at least to ratify with deep commitments). Similarly, an agreement that includes potent type 1 and type 3 incentives, but not potent type 2 incentives, would likely experience considerable withdrawals. Finally, an agreement that provides potent type 1 and type 2 incentives, but not potent type 3 incentives, would likely witness widespread noncompliance.

In short, were an ambitious climate agreement to include only one or two types of potent incentives, enforcement would largely shift free-riding behavior from categories for which the agreement includes potent enforcement (say, noncompliance and withdrawal) to categories for which the agreement provides no enforcement (say, nonratification or ratification with a shallow commitment). Enforcement would then add little to the agreement's effectiveness (e.g., [20]). An effective climate agreement must therefore block all escape options for would-be free riders by providing potent enforcement of all three types.

While potent enforcement is essential for an effective climate agreement, it is not equally important for making other IEAs effective. Although only relatively few IEAs include potent enforcement measures, it is well known (e.g., see [21]) that many IEAs experience high compliance rates (however, it is also true that some IEAs have witnessed considerable noncompliance -the Gothenburg Protocol under the Convention on Long-range Transboundary Air Pollution provides an example). At least four factors may explain high compliance rates in IEAs without potent enforcement (e.g., see [22]). Firstly, IEAs aiming to solve a coordination game rather than a social dilemma game provide no incentives for noncompliance. Secondly, we should also expect high compliance rates for shallow dilemma-game IEAs, where member countries are committed to little more than business as usual. Thirdly, even deep dilemma-game IEAs may obtain high compliance (and participation) rates if the problem size is moderate, so that compliance costs are also moderate. In such cases, the legal principle of pacta sunt servanda and other cooperation norms may well overcome the incentive to free ride. Finally, in dilemma-game IEAs without potent incentives to ratify, would-be free riders will likely opt out of the agreement, meaning that only countries able and willing to fulfill their commitments will participate. Importantly, climate change constitutes a large and extremely malign social dilemma that involves very high costs because virtually all economic activities entail GHG emissions (see Section 2). The need for potent enforcement will therefore likely be considerably larger for an (ambitious) climate agreement than for almost any other IEA.

\subsection{Kyoto: A Climate Agreement without Potent Enforcement}

The requirement that enforcement must be potent might seem self-evident; however, Kyoto's enforcement system illustrates that enforcement institutions might fall significantly short of meeting the requirement that an effective agreement must include potent incentives of all three types.

Firstly, while Kyoto (or rather, its companion agreement, the Marrakesh Accords from 2001) included incentives for compliance enforcement (type 3 incentives), it did not include incentives for countries to abstain from withdrawal (type 2 incentives). Hence, Canada could essentially withdraw from Kyoto at little or no cost.

Secondly, neither the Kyoto Protocol nor the Marrakesh Accords includes any incentives for inducing countries to ratify Kyoto. Such incentives were nevertheless used informally by some Kyoto members vis-à-vis some other Annex I countries. In particular, while initially hesitant, Russia eventually ratified Kyoto in return for the EU's dropping its objections against Russia's joining the World Trade Organization [23]. After the United States' repudiation, Kyoto could not have entered into force without Russian ratification, because entry into force required ratification by at least 55 countries responsible, in total, for at least $55 \%$ of the 1990 emissions in Annex I countries. After 
the U.S. repudiation of Kyoto, the latter requirement could not be met without Russian ratification.

Finally, the compliance incentives included in the Marrakesh Accords suffer from severe problems. The Accords specify that countries failing to submit sufficient permits to cover their emissions in the first commitment period (2008-2012) face two main consequences:

1. They must compensate for their excess emissions in the second commitment period (which has now been set to 2013-2020). Moreover, in the second commitment period, noncompliant countries must reduce their emissions by an additional $30 \%$ of their surplus in the first commitment period. These emissions reductions come on top of whatever noncompliant countries' emissions reductions commitments might be for the second commitment period;

2. They will have their eligibility to participate in emissions trading suspended until this eligibility is reinstated by the Enforcement Branch of the Compliance Committee. In practice, suspension means that they will be unable to sell (but can buy) emission permits.

A main problem with the first consequence is that it essentially requires noncompliant countries to punish themselves [17]. Furthermore, this self-punishment requirement is voluntary in a three-fold sense. Firstly, the obligation to undertake additional emissions reductions is not legally binding. Secondly, no secondorder punishment exists for failure to implement the punishment. In other words, noncompliant countries risk nothing for failing to punish themselves. Thirdly, the consequence presupposes that noncompliant countries will voluntarily continue as members in the second commitment period. Noncompliant countries can thus escape punishment by simply withdrawing from the treaty. As already mentioned, Canada withdrew from Kyoto before the first commitment period ended, whereas several other countries (Belarus, Japan, New Zealand, Russia, and Ukraine) have declined to participate in Kyoto 2.

The second consequence does not rely on selfpunishment, because the climate regime controls who can and who cannot legitimately participate in emissions trading. Indeed, emissions trading makes little sense unless approved by the climate regime. Nevertheless, even this consequence lacks "bite": to sell emissions permits, a country must have a surplus of permits. In contrast, a noncompliant country will have a deficit of permits and will thus have no permits to sell. At best, therefore, the second consequence contributes to preventing noncompliant countries from illegally selling permits they do not have.

Because Kyoto's enforcement system is so lacking in potency, it is practically useless as a deterrent of excess emissions and will unlikely have much influence on member countries' compliance. However, in the case of Kyoto, the absence of potent enforcement may not have made much of a difference. Firstly, Kyoto aimed only at moderate emissions reductions (on average about $5.2 \%$ reduction in Annex I countries, compared to 1990 levels); thus, incentives for noncompliance were correspondingly moderate.

Secondly, the economic downturn following the financial crisis contributed significantly to limiting emissions in the 2008-2012 period, thereby reducing the cost of compliance in Kyoto's first commitment period even further.

Thirdly, for many or even most of the 36 countries with a legally binding emissions reduction or limitation commitment we should expect high compliance rates for reasons that have nothing to do with Kyoto's enforcement system. Twenty-seven of these 36 countries are EU members and 3 additional countries are members of the European Economic Area (EEA). The EU has strong ambitions to act as an international leader on climate change mitigation, and can rely on far more potent means of enforcement than Kyoto can. Examples include the European Court of Justice and the very potent enforcement measures included in the EU ETS (e.g., see [24]). Moreover, of the remaining six Kyoto countries with a binding emissions reduction or limitation commitment, three (Belarus, Russia, and Ukraine) received a large surplus of permits ("hot air") because of their transition to a market economy following the fall of the communist regimes around 1990 (the same is true for the eight former communist countries that are now EU members). Thus, these countries did not have to actively limit their emissions to reach compliance. Also, Japan was probably exceptionally motivated to comply because of the name and origin of the Kyoto Protocol.

Finally, participation in Kyoto was completely voluntary in that no incentives were included for ratification or against withdrawal. Countries that participate voluntarily in an IEA will likely display a reasonably high motivation for compliance [25].

All these factors suggest that Kyoto enjoyed quite favorable conditions concerning compliance rates. Nevertheless, based on emissions data excluding land use, land use changes, and forestry (LULUCF) for the 2008-2010 period, Haita found that no less than 15 member countries had on average exceeded their yearly national quota $([26]$, p. 2). Seemingly, for at least some of them, only creative accounting or massive acquisition of credits through emissions trading, joint implementation, and the clean development mechanism in the commitment period's final two years would make compliance possible [27].

That Kyoto struggled to achieve high compliance rates despite the many favorable conditions underlines the importance of potent enforcement. To ensure comprehensive and stable participation in a more effective future climate agreement, incentives for ratification with deep commitments and incentives against withdrawal may be necessary. Countries induced to 
participate through such incentives may well drag their feet concerning compliance unless the agreement also includes potent compliance enforcement. Hence, including incentives for ratification and against withdrawal will likely enhance the need for compliance enforcement $[24,28]$. This hypothesis is consistent with our earlier claim that including only one or two forms of enforcement-but not all three-will unlikely add much to an agreement's effectiveness.

\subsection{Potent Enforcement: An Example}

If Kyoto's enforcement system is impotent, what might a potent enforcement system look like? Proposed alternatives include enforcement via GHG abatement reductions, trade restrictions, or by restricting access to R\&D cooperation. However, such systems often fail to meet the conditions for a potent enforcement system discussed in Section 3.2, and would therefore be incapable of deterring free riding [29]. This section considers an example of a simple yet potent enforcement system that could in principle be incorporated into a new climate agreement. Based on deposits, this system would provide big and credible incentives for compliance and could easily be adapted to provide equally big and credible incentives against withdrawal. However, although in theory the system could also be designed to provide big incentives for ratification with deep commitments, these incentives would unlikely be credible in practice. The system would therefore require that other measures (e.g., some kind of trade restrictions) be added to provide potent incentives for ratification with deep commitments.

Several scholars (e.g., [29-35]) have considered possibly enforcing a new climate agreement through a deposit-refund system. The design of such a system must take into account the type of climate agreement concerned; here we consider a design for a cap-andtrade agreement (e.g., [29,36]). Essentially, each member country must (1) deposit a significant sum of hard currency at ratification and (2) make additional periodic deposits until the commitment period begins. When it ends, a country that makes all required deposits and meets its emissions limitation target will receive a full refund. In contrast, a country that fails to make further required deposits or fails to reach its target will lose all or part of its existing deposits, depending on the degree of its noncompliance. Provided that for each country the total deposits exceed the cost of reaching the target, this depositrefund system will effectively deter excess emissions.

As an instrument for compliance enforcement, a deposit-refund system has several advantages [29]. Firstly, it is simple. Whereas Kyoto's compliance enforcement system is fairly complex, almost anyone can understand a system whereby excess emissions will entail loss of deposits. Secondly, unlike Kyoto's reliance on self-punishment, confiscation of deposits does not require self-damaging cooperation by the country concerned, because the climate regime will control deposits. Thirdly, provided that each country's total deposits exceed its costs of reaching its target, the punishment for noncompliance will be sufficiently big: fulfilling commitments and receiving a full refund will be better than being noncompliant and forfeiting (part of) deposits. Finally, the threatened punishment will also be credible: punishing a noncompliant party will benefit other parties individually as well as collectively.

Under Kyoto, a noncompliant country could escape punishment simply by withdrawing (as Canada did). In contrast, a deposit-refund system could easily be designed to make such escape unprofitable. For example, the agreement could specify that upon withdrawing, a member country forfeits some (or even all) of its deposits.

What about incentives for ratification? In theory, a deposit-refund system may also be designed to induce countries to ratify. In particular, in a symmetric setting (i.e., all countries are identical), a clause could specify that the treaty will not enter into force until all countries have ratified with deep commitments and made the required deposits [29]. Such a clause would effectively make free riding by not ratifying (or by ratifying without a deep commitment) infeasible.

In practice, however, a deposit-refund system is implausible as an instrument for inducing ratification. Firstly, the climate change problem is entangled in many and serious asymmetries (e.g., [37]), which makes requiring all countries to participate extremely impractical. Secondly, the multiple asymmetries make unlikely a consensus on relaxing the universal participation requirement: permitting some (major) countries to free ride would unlikely obtain unanimous consent. Thirdly, relaxing the unanimous ratification requirement could undermine the incentive to join; indeed, if an agreement requires only partial participation and does not provide other incentives for participation, a depositrefund system could even undermine cooperation $[34,35]$. Fourthly, it may not be credible that if one country declines to make the deposit required upon ratification, other countries will abstain from cooperating among themselves. Yet, in a deposit-refund system, the incentive to ratify and make deposits critically hinges on such credibility. Finally, countries facing serious liquidity problems (e.g., several southern European countries) may be particularly reluctant to participate in a climate treaty based on a depositrefund system.

In conclusion, a deposit-refund system could provide sufficiently big and credible incentives for compliance and against withdrawal. It could also solve many problems associated with Kyoto's enforcement system. However, a deposit-refund system provides less powerful incentives for ratification with deep commitments. It must therefore be combined with other measures, such as a set of (carefully selected) trade restrictions, to induce comprehensive participation [38]. 
An agreement with a deposit-refund system would also have to overcome other challenges. Member countries would face uncertainty concerning the size of the required deposits. They must ensure that the risk of deposits being lost be no bigger than the corresponding risk for alternative investments. Some countries (such as Norway) may be able to pay the deposits; countries with severe liquidity problems may not be able to pay them, at least not until the financial crisis ends.

These and other practical challenges may or may not have practical solutions; however, for the sake of argument, let us assume that they are solvable or that someone conceives of potent enforcement that entails no unsolvable practical challenges. The question would still remain: is potent enforcement politically feasible?

\subsection{Is Potent Enforcement Politically Feasible within the UNFCCC?}

Decision rules, that is, the level of support required for collective decisions, are a key determinant of political feasibility [39]. Climate negotiations take place within the UNFCCC, which operates under consensus rules. These decision rules give veto power to the most reluctant countries. The consensus requirement is not always taken literally. At the 18th Conference of the Parties (COP-18) in Doha in 2012, for instance, protests from Russia, Ukraine, Belarus, and Kazakhstan were ignored when the Doha decisions were adopted (see, e.g., [40]). However, such occasional "liberal" implementation of the consensus principle does not solve the problem of giving veto power to the most reluctant countries; at best, such implementation might postpone it.

Countries that are generally negative towards a deep agreement will likely oppose potent incentives for ratification and potent incentives against withdrawal. Countries uncertain about their own willingness or ability to implement their commitments will likely oppose potent enforcement of compliance. Furthermore, the deeper the commitments, the larger the need for potent enforcement and the more likely that some countries will oppose such enforcement [11]. As long as some of the UNFCCC's 195 parties are unprepared to consent to deep commitments and/or potent enforcement, a climate agreement which includes all three types of enforcement required for an agreement to be effective is politically infeasible. For example, India is currently unprepared to consent to an agreement with deep commitments and potent enforcement, as illustrated by the following statement: "developing countries need not have a compliance regime even though the new treaty or Arrangement could apply to all Parties. This is because the targets of developing countries will need to continue to be voluntary" [41]. A climate agreement with deep commitments and potent enforcement mechanisms will therefore be politically infeasible if negotiated within the UNFCCC framework (or, for that matter, within any other global forum based on unanimity).

\section{The Feasibility of an Indirectly Effective Climate Agreement}

We now turn to the prospects for an indirectly effective climate agreement. As noted above, $\mathrm{CO}_{2}$ emissions are unevenly distributed among UNFCCC parties: fewer than 20 countries are responsible for more than $80 \%$ of global emissions [42]. Also, there is a principal difference between the three enforcement types. Clearly, all three will likely require unanimity among the negotiating parties. However, whereas incorporating incentives for compliance and against withdrawal will also require unanimity amongst the affected countries, incentives for ratification with deep commitments can be incorporated without requiring unanimity amongst affected countries ([43], p. 4). Thus, even if an effective all-party climate agreement with potent enforcement mechanisms is politically infeasible in the UNFCCC context, a gradual approach to establishing an effective all-party agreement might nevertheless be feasible.

A possible way to proceed could be as follows: first negotiate a deep agreement with incentives for compliance and against withdrawal amongst an initial coalition of willing key actors, and then elicit the participation of reluctant countries (i.e., countries that would not have consented to the agreement, had they participated in negotiating it) by incorporating incentives to ratify with deep commitments ([43], p. 4). Whether a country may be considered "key" in this context depends on two factors: the first is its share of global emissions, which reflects its significance in mitigating climate change. The second is its economic power, which reflects its capacity to implement measures that can effectively induce reluctant parties to participate. In climate negotiations, however, these features overlap in that the largest emitters also generally have very large economies.

In 2008 , seven actors were responsible for $73 \%$ of global $\mathrm{CO}_{2}$ emissions: China (23\%), the United States $(19 \%)$, the EU (13\%), India (6\%), Russia (6\%), Japan (4\%), and Canada (2\%) [44]. Thus, a climate agreement that includes these seven would control a very large share of global emissions and have tremendous economic leverage. However, the number of key actors could be even further restricted to include only China and the United States. Between them, they account for $42 \%$ of global $\mathrm{CO}_{2}$ emissions [43] and more than $30 \%$ of world GDP [45]. If they were to agree on deep commitments to reduce GHG emissions and on potent mechanisms to enforce compliance, they would likely have the economic strength to induce reluctant countries to join, for instance by implementing trade restrictions against nonparticipants. The question is: can they reach such an agreement?

Since 2005-2006, we have seen a development in China towards more ambitious domestic climate policies, 
including significant investments in renewable energy sources (solar, wind power, and hydroelectric power) and energy efficiency. China has also introduced a national resources tax that includes fossil energy resources [46]. Prior to the COP-15 in Copenhagen, China announced an unconditional national carbon intensity reduction target of $40-45 \%$ from its 2005 level by 2020 [47]. So far, however, these domestic developments have not translated into a more ambitious Chinese approach at the international level. Since the climate issue surfaced on the international agenda in the late 1980s, China has consistently argued that it will not commit to international GHG reduction targets until developed countries (notably the United States) demonstrate willingness and ability to reduce their GHG emissions. Whether domestic developments may evoke changes in China's future international position is difficult to assess. On the one hand, China increasingly recognizes its vulnerability to climate change, which implies a stronger interest in a potent international agreement to mitigate climate change. On the other hand, however, China's domestic climate measures also seem motivated by the government's effort to restructure China's economic model and may be beneficial in their own right [47]. Conrad thus suggests that for China, "strapping itself into the confines of an international climate framework including binding emission reductions...comes with great political risk" [47]. In the Copenhagen negotiations, China adopted its traditional position that the main responsibility for abating the climate problem lies with developed countries. This position was reiterated later. In a February 2012 joint statement, the BASIC group, which is the main coalition of large developing countries or "emerging economies" [48], stated: "developed countries must rise up to their historical responsibilities and take the lead in the fight against climate change...in accordance with the principles of equity and common but differentiated responsibilities and respective capabilities under the Convention" [49]. Equally important in this context is that China is opposed to any climate agreement negotiated outside the UNFCCC framework. In a position paper prior to COP-15 in Copenhagen in 2009, China stated, "the UNFCCC and its Kyoto Protocol constitute the basic framework and legal basis for international cooperation to address climate change" [50].

Even if China should be prepared to undertake substantial GHG emissions mitigation, however, it is unlikely that China would also be prepared to accept potent enforcement mechanisms. China's position is that developing countries (including China) should not be required to take on quantified emissions reduction commitments, but may voluntarily agree to "Nationally Appropriate Mitigation Actions" initiated by themselves, enabled through technological and financial transfers by developed countries, and exempt from any form of enforcement measures [51-53]. China's resistance to potent enforcement can in part be traced to concerns with preserving national sovereignty, and in part with a general reluctance to incorporating potent enforcement unless prospects for compliance are certain [51]. Regarding enforcement of ratification, the BASIC countries, including China, "are concerned that unilateral trade restrictions (i.e., any type of trade restriction not agreed on unanimously by all UNFCCC parties) will distort international trade, thereby undermining economic development in developing countries" ([43], p. 15).

The United States, on the other hand, is reluctant to join an international climate agreement that does not include GHG emissions control targets for large developing countries (notably China). The United States accepted the principle of "common but differentiated responsibilities" adopted in the UNFCCC (Article 4.1), but it opposes a continued practice whereby countries (such as China) are exempted from GHG control measures, as the Senate's 1997 Byrd-Hagel Resolution made clear. It declares:

"the United States should not be a signatory to any protocol...which would...mandate new commitments to limit or reduce greenhouse gas emissions for the Annex I Parties [i.e., Developed Country Parties], unless the protocol...also mandates new specific scheduled commitments...for Developing Country Parties within the same compliance period..." [54].

China and India are currently responsible for almost $30 \%$ of global GHG emissions, and their emissions are increasing at a faster rate than those of any other country (see, e.g., [55]).

Furthermore, China is a main competitor to the United States in the global market, and there is widespread concern among U.S. decision-makers that U.S. GHG emissions reduction measures that are not reciprocated, particularly by China, will put U.S. industries at a competitive disadvantage $[56,57]$. GHG emissions regulations encounter strong domestic opposition in the United States. The U.S. Senate has rejected legislative proposals for domestic GHG control measures three times (2003, 2005, and 2008). In 2009, federal climate legislation was adopted by the U.S. House of Representatives, but the legislation was never put to a floor vote in the Senate and was thus never enacted as U.S. law.

This lack of federal climate legislation does not mean that there are no actions in the United States to reduce GHG emissions. For instance, following a 2007 Supreme Court decision permitting $\mathrm{CO}_{2}$ regulations under the Clean Air Act, the Obama Administration instructed the U.S. Environmental Protection Agency (EPA) to develop and enforce $\mathrm{CO}_{2}$ emissions regulations on both mobile (e.g., transportation) and permanent sources (e.g., coal-fired power plants). In addition, there are several climate initiatives taking place at state level. The most important is the Regional Greenhouse Gas Initiative (RGGI), an emissions trading system that includes a number of states in the northeastern region of the country $[57,58])$. Finally, since ca. 2006 we have seen a significant decline in U.S. energy- 
related $\mathrm{CO}_{2}$ emissions, a decline due to the shift from coal to gas following from the tremendous increase of shale gas in the U.S. energy mix for electricity production (e.g., see [59]). The national and sub-national initiatives, however, will unlikely generate the required scope of emissions reductions. Moreover, there is currently limited political support for policy measures to ensure a permanent transition from coal to gas in U.S. electricity generation, such as a carbon tax or a similar policy measure [60]. The long-term effect of the U.S. "shale gas revolution" is thus uncertain. None of these initiatives and developments, therefore, ensures the legislative foundation required for U.S. ratification of a new climate agreement.

Were the United States to sign and ratify an agreement to reduce GHG emissions, however, U.S. commitments incorporated in the agreement would become part of "the supreme law of the land" and would thus be subject to the same strict compliance regime that governs all federal U.S. legislation (e.g., see $[61,62]$ ). In the United States, therefore, compliance is already enforced in the federal judicial system. The United States thus often supports strong international mechanisms to enforce compliance and to make sure its international counterparts face similar provisions. For instance, in the negotiations over Kyoto's compliance system, the United States consistently supported strong enforcement ([63], pp. 24-26).

The United States also supports enforcement of ratification. In the domestic debate on GHG control measures, legislative proposals have invariably included measures that could be used to sanction nonparticipation, usually in the form of some kind of border tax. In the United States, therefore, it is not enforcement mechanisms that generate opposition, but rather GHG control measures.

Given the major positions China and the United States occupy in the world economy, a climate agreement in which neither or just one of these key actors participates with deep commitments would not satisfy our requirements of an effective agreement. The United States and China, however, have been locked in a relationship of mutually incompatible positions at least since the late 1990s. China is not prepared to accept deep international GHG commitments until developed countries, particularly the United States, take on such commitments. The United States, on the other hand, is not prepared to take on international GHG reduction commitments unless major developing countries, such as China, do so. Given these key actors' dominant economies and their political positions on the climate problem, even an indirect (gradual) approach to establishing an international climate agreement with deep commitments and potent enforcement would likely be politically infeasible.

\section{Conclusions}

More than two decades of climate change negotiations have produced a series of climate agreements. Nevertheless, the negotiations have been largely unsuccessful, because none of these agreements has contributed much to solving the climate change problem. We argue that one should not expect future climate change negotiations to directly or indirectly produce an effective agreement either. An argument consisting of four main elements supports this conclusion.

Firstly, an ambitious agreement will likely entail very strong incentives for free riding. In particular, these incentives will be much stronger for an ambitious future climate agreement than the corresponding incentives for free riding in past, less ambitious climate agreements (Kyoto). They will also be much stronger than the incentives for free riding in ambitious IEAs in other issue areas (e.g., Montreal).

Secondly, curbing these strong incentives for free riding will require three types of potent enforcement: incentives to ensure that all major countries ratify with deep commitments, incentives to ensure that ratifiers with deep commitments do not withdraw, and incentives to ensure that ratifiers with deep commitments comply with them.

Thirdly, adoption of such three-fold potent enforcement will almost certainly be politically infeasible within the UNFCCC, which operates under consensus rules that grant veto power to the most reluctant countries. Countries that are generally negative to an agreement will likely oppose potent incentives for ratification with deep commitments as well as potent incentives against withdrawal. Moreover, countries willing to participate with deep commitments but uncertain about their own willingness or ability to implement these commitments will likely oppose potent enforcement of compliance. The larger the incentives for free riding (the deeper the commitments), the larger the need for potent enforcement and the more likely that some countries will oppose such enforcement. Thus, while we agree with Barrett $[17,20]$ that potent enforcement is essential for an effective climate agreement, we are perhaps even less optimistic than he is concerning the likelihood that it will be feasible to incorporate potent enforcement measures in a future climate agreement.

Finally, a gradual approach that aims to reach an effective agreement indirectly and that is based on a more limited set of negotiating parties outside the UNFCCC, will be unlikely to succeed either. While such a process may have some advantages in principle, a successful outcome requires participation by both China and the United States. Unless they can somehow join forces, negotiations will be no more likely to succeed outside the UNFCCC than inside it.

The conclusion that global negotiations are likely to fail is not new. Scholars and environmentalists alike regard global negotiations as likely to fail. For example, David Victor argues that climate diplomacy has yielded "the illusion of action but not much impact on the underlying problem" [37] and David Roberts argues 
that "the notion that smaller groups than the UNFCCC are needed for serious climate negotiations is now practically conventional wisdom in developed countries" [64]. However, our analysis differs from theirs in at least two respects. Firstly, unlike Victor and Roberts, we argue that a more gradual approach is also likely to fail. Secondly, unlike them, we emphasize that potent enforcement is not only required to make a climate agreement effective, but also highly unlikely to be politically feasible.

Readers will likely consider our conclusions as depressing news. However, in our view it is better to adjust the expectations of (and perhaps even the goal of) the climate change negotiations than to continue

\section{References and Notes}

1. PBL Netherlands Environment Assessment Agency. Long-term trend in global $\mathrm{CO} 2$ emissions; 2011 report. Available from: http://www.pbl.nl/en/pu blications/2011/long-term-trend-in-global-co2-emissio ns-2011-report (accessed on 7 May 2013).

2. Bäckstrand studies a similar question (using a very different approach). See: Bäckstrand K. Kan klimathotet avvärjas genom internationella förhandlingar? In: Bennich-Björkman L, editor. Statsvetenskapens frågor. Stockholm, Sweden: Studentliteratur; 2013. pp. 243-253.

3. Hovi J, Sprinz DF, Bang G. Why the United States did not become a party to the Kyoto Protocol: German, Norwegian and US perspectives. European Journal of European Relations. 2012;18(1):129-150.

4. We ignore the possibility of a long series of agreements, each of which reduces global emissions only slightly. This possibility would likely work too slowly to have any chance of avoiding dangerous climate change.

5. United Nations Framework Convention on Climate Change. Available from:http://unfccc.int/resourc e/docs/cop1/07a01.pdf (accessed on 5 August 2013).

6. Edwards PN, Schneider SH. Self-governance and peer review in science-for-policy: The case of the IPCC Second Assessment Report. In: Miller CA, Edwards PN, editors. Changing the Atmosphere: Expert Knowledge and Environmental Governance. Cambridge, MA, USA: MIT Press; 2001. pp. 219-246.

7. For excellent accounts of the expectations to, and the outcome of, the 2009 Copenhagen meeting, see: Kulovesi K, Gutiérrez M. Climate change negotiations update: Process and prospects for a Copenhagen agreed outcome. Review of European Community and International Environmental Law. 2009;18(3):229-243 and Dimitrov RS. Inside UN climate change negotiations. Review of Policy Research. 2010;27(6):795-821.

8. How long it takes before climate mitigation takes effect depends in part on the composition of gases that are reduced. Whereas some GHGs have atmospheric lifetimes of several hundred years (and thus will continue to affect the global climate several hundred years after their emission), other GHGs have upholding an illusion that ambitious goals will be achieved eventually, when such goals are in fact politically infeasible. Only by developing a realistic view of the process and its prospects can we hope to get the best out of it.

\section{Acknowledgments}

We are indebted to two anonymous reviewers for many helpful comments and to Frank Azevedo for excellent editorial assistance. Aakre and Hovi gratefully acknowledge financial support from the Research Council of Norway through grant no. 185508 (Aakre) and grant no. 20971/E20 for CICEP (Hovi).

shorter atmospheric lifetimes. But a time lag of at least several decades between costs and effects of GHG emissions reductions is likely (e.g., see [65]).

9. EurActiv. EU summit set to turn climate agenda upside down; 22 May 2013. Available from: http:// www.euractiv.com/energy/energy-council-set-turn-euclima-news-519883?utm_source=EurActiv\%20Newsle tter\&utm_campaign=ec7702722f-newsletter_energy\& utm_medium =email\&utm_term $=0$ _bab5f0ea4e-ec770 2722f-245302445 (accessed on 29 July 2013).

10. Statement by Minister Kent, issued by Environment Canada; 12 December 2011. Available from: http://www.ec.gc.ca/default.asp?lang $=$ En\&n=FFE36B 6D-1\&news=6B04014B-54FC-4739-B22C-F9CD9A8408 00 (accessed on 13 February 2013).

11. Hovi J, Sprinz DF, Underdal A. Implementing long-term climate policy: Time inconsistency, domestic politics, international anarchy. Global Environmental Politics. 2009;9(3):20-39.

12. We do not imply that the different types of free riding listed here are equivalent from a moral viewpoint. Rather, we use "free rider" as a technical term that covers any country benefiting from, but not contributing to, the effort to reduce global GHG emissions.

13. In the UNFCCC, the parties that have taken on the commitments defined in Article 4.2 are listed in Annex I of the Convention and are thus often referred to as Annex I countries.

14. UNEP. Global green new deal. United Nations Environment Program; 2009. Available from: http:// www.unep.org/pdf/G20_policy_brief_Final.pdf (accessed on 31 May 2013).

15. Downs GW, Rocke DM, Barsoom PN. Is the good news about compliance good news about cooperation? International Organization. 1996;50(3):379-406.

16. Examples of IEAs in which participants have committed to little more than business as usual include the Basel Convention (e.g., see [66]), the Helsinki Protocol (e.g., see [67]), the Kyoto Protocol (e.g., see [68]) and the Oslo Protocol (e.g., see [69]).

17. Barrett S. Environment and Statecraft: The Strategy of Environmental Treaty-Making. Oxford, UK: Oxford University Press; 2003. 
18. Breitmeier $\mathrm{H}$, Young OR, Zürn M. Analyzing International Environmental Regimes. From Case Study to Database. Cambridge, MA, USA: MIT Press; 2006.

19. A focus on benefits as well as costs seems to reflect the reality of climate change negotiations. See Dimitrov R. The politics of persuasion: U.N. climate change negotiations. In: Dauvergne $\mathrm{P}$, editor. Handbook of Global Environmental Politics. Cheltenham, UK: Edward Elgar; 2012. pp. 72-86.

20. Barrett S. Climate treaties and the imperative of enforcement. Oxford Review of Economic Policy. 2008; 24(2):239-258.

21. Bodansky D. The Art and Craft of International Environmental Law. Cambridge, MA, USA: Harvard University Press; 2009.

22. Grundig F, Hovi J, Underdal A, Aakre S. Selfenforcing peace and environmental agreements. International Studies Review. 2012;14(4):522-540.

23. Walsh NP. Russian vote saves Kyoto protocol. The Guardian; 2004. Available from: http://www.guar dian.co.uk/world/2004/oct/23/society.russia (accessed on 31 May 2013).

24. Aakre S, Hovi J. Emission trading: Participation enforcement determines the need for compliance enforcement. European Union Politics. 2010;11(3):427445.

25. Because IEAs with voluntary participation are likely to display high compliance levels, a constructivist theorist might argue that one should look for sources of potential voluntary cooperation on climate change mitigation, based on principles rather than interests. While we agree that principles may also be important in motivating countries' behavior, it seems plausible to assume that their motivating force would likely be stronger, the lower the costs of compliance. In issue areas such as climate change, participating in and complying with an IEA might entail substantial adverse economic effects and only limited positive environmental effects. Self-interest might therefore strongly tempt countries to free ride one way or the other. Potent enforcement will be required to restructure such free-rider incentives.

26. Haita C. The state of compliance in the Kyoto Protocol. ICCG Reflection No. 12/2012. Available from: http://www.iccgov.org/FilePagineStatiche/Files/Publica tions/Reflections/12_Reflection_December_2012.pdf (accessed on 28 May 2013). These countries were, in decreasing order of excess emissions, Luxembourg, Austria, Iceland, New Zealand, Australia, Liechtenstein, Spain, Denmark, Switzerland, Slovenia, Norway, Italy, Japan, Netherlands, and Ireland.

27. Unfortunately, although the first commitment period ended on 31 December 2012, and the additional grace period of 100 days available for credit acquisition ended in April 2013, the final data on compliance are not yet available at the time of writing.

28. Aakre S, Helland L, Hovi J. What types of enforcement matter? An experimental study. Unpublished working paper; 2013.
29. Hovi J, Greaker M, Hagem C, Holtsmark B. A credible compliance enforcement system for the climate regime. Climate Policy. 2012;12(6):741-754.

30. Gersbach $H$. A new way to address climate change: A global refunding system. The Economist's Voice. 2008;5(4):1-4.

31. Finus $M$. The enforcement mechanisms of the Kyoto Protocol: Flawed or promising concepts? Letters in Spatial and Resource Sciences. 2008;1(1):13-25.

32. Gerber A, Wichardt PC. Providing public goods in the absence of strong institutions. Journal of Public Economics. 2009;93(3-4):429-439.

33. Gersbach $H$, Winkler R. Global refunding and climate change. Journal of Economic Dynamics and Control. 2012;36(11):1775-1795.

34. McEvoy DM. Enforcing Compliance with international environmental agreements using a depositrefund system. International Environmental Agreements; Forthcoming.

35. Cherry TL, McEvoy DM. Enforcing compliance with environmental agreements in the absence of strong institutions: An experimental analysis. Environmental and Resource Economics. 2013;54(1):63-77.

36. A design for an agreement based on carbon emission taxes is analyzed by Gersbach and Winkler [33].

37. Victor DG. Global Warming Gridlock. Cambridge, MA, USA: Cambridge University Press; 2011.

38. Many scholars have warned that using trade restrictions to induce participation (or compliance) in a future climate treaty could damage the international trade system. This issue is too big to be considered here.

39. Skodvin T, Gullberg AT, Aakre S. Target-group influence and political feasibility: The case of climate policy design in Europe. Journal of European Public Policy. 2010;17(6):854-873.

40. Korppo A. The Doha dead end? Transition economies and the new Kyoto Rules. FNI Climate Policy Perspectives 9. Oslo, Norway: The Fridtjof Nansen Institute; 2013.

41. Indian Ministry of Environment and Forests. Frequently asked questions on India and the Durban Platform. Available from: http://moef.nic.in/modules/o thers/?f=durban-faqs (accessed on 28 May 2013).

42. United Nations Statistics Division. Millennium development goals indicators: Carbon dioxide emissions 1990-2009. Available from: http://mdgs.un. org/unsd/mdg/SeriesDetail.aspx?srid=749 (accessed on 29 April 2013).

43. Aakre S. The political feasibility of potent enforcement in a post-2012 climate agreement. Unpublished working paper; 2013.

44.U.S. Environmental Protection Agency. Global Greenhouse Gas Emissions Data. Available from: http://www.epa.gov/climatechange/ghgemissions/glo bal.html (accessed on 29 April 2013).

45. The GDP estimate is based on 2011 data from the United Nations Statistics Division. Available from: http://en.wikipedia.org/wiki/List_of_countries_by_GDP _(nominal) (accessed on 29 April 2013). 
46. McKenna M. China not waiting for U.S. to lead on climate. The Diplomat; 29 July 2013. Available from: http://thediplomat.com/china-power/china-notwaiting-for-the-us-to-lead-on-climate/ (accessed on 29 July 2013).

47. Conrad B. China in Copenhagen: Reconciling the 'Beijing climate revolution' and the 'Copenhagen climate obstinacy'. The China Quarterly. 2012;210(June): 435-455.

48. The BASIC group includes China, India, Brazil, and South Africa.

49. Statement at the 10th BASIC ministerial meeting on climate change in New Delhi, February 2013. Available from: http://www.trademarksa.org/news/bas ic-ministerial-meeting-climate-change-communique-0 (accessed on 29 April 2013).

50. Implementation of the Bali Roadmap: China's Position on the Copenhagen Climate Conference. Issued by National Development and Reform Commission (NDRC), People's Republic of China; 20 May 2009. Available from: http://en.ndrc.gov.cn/newsrelea se/t20090521_280382.htm (accessed on 29 April 2013).

51. Held D, Nag E-M, Roger C. The governance of climate change in developing countries. A report on international and domestic climate change politics in China, Brazil, Ethiopia and Tuvalu. London, UK, and Paris, France: LSE Global Governance; 2012

52. Teehanke MAJ, Jegou I, Rodrigues RJ. Multilateral negotiations at the intersection of trade and climate change: An overview of developing countries' priorities in the UNCSD, UNFCCC and WTO processes. Climate Change Architecture Series. Geneva, Switzerland: ICTSD Program on Global Economic Policy and Institutions; 2012.

53. Fang S-h. Governing carbon: China in Global Climate Politics. PhD Thesis, University of Sussex; 2012.

54. Senate Resolution 98. Congressional record, Report No. 105-5412, 25 July 1997.

55. Raupach MR, Marland G, Ciais P, Le Quéré C, Canadell JG, Klepper G, Field CB. Global and regional drivers of accelerating $\mathrm{CO} 2$ emissions. Proceedings of the National Academy of Sciences (PNAS). 2007;104 (24):10288-10293.

56. Asselt HV, Brewer HAT, Mehling M. Addressing leakage and competitiveness in U.S. climate policy: Issues concerning border adjustments. Working Paper. Cambridge, UK: Climate Strategies; March 2009.

57. Rabe BG. Statehouse and Greenhouse: The
Emerging Politics of American Climate Change Policy. Washington, DC, USA: The Brookings Institution; 2004.

58. Depledge J. Against the grain: The United States and the global climate regime. Global Change, Peace \& Security. 2005;17(1):11-27.

59. EIA (Energy Information Administration). Annual Energy Outlook 2013: Early release overview. Available from: http://www.eia.gov/forecasts/aeo/er/pdf/0 383er(2013).pdf (accessed on 24 February 2013).

60. Bang G, Skodvin T. U.S. climate policy and the shale gas revolution. In: Cherry T, Hovi J, McEvoy D, editors. Toward a New Climate Agreement: Conflict, Resolution and Governance. London, UK: Routledge; forthcoming 2014.

61. Skodvin T, Andresen S. An agenda for change in U.S. climate policies? Presidential ambitions and congressional powers. International Environmental Agreements. 2009;9(3):263-280.

62. Fisher DR. National Governance and the Global Climate Change Regime. Lanham, MD, USA: Rowman \& Littlefield Publishers; 2004.

63. Werksman J. The negotiation of a Kyoto compliance system. In: Stokke OS, Hovi J, Ulfstein G, editors. Implementing the Climate Regime: International Compliance. London, UK: Earthscan Press; 2005. pp. 17-37.

64. Roberts D. A way to win the climate fight? The American Prospect. Available from: http://prospect.org/ article/way-win-climate-fight (accessed on 21 July 2013).

65. Fuglestvedt JS, Berntsen T, Godal O, Sausen R, Shine KP, Skodvin T. Metrics of climate change: Assessing radiative forcing and emission indices. Climatic Change. 2003;58(3):267-331.

66. Kellenberg D, Levinson A. Waste of effort? International environmental agreements. Paper presented at the Stanford Institute for Theoretical Economics Summer 2013 Workshop, Stanford, CA, USA, 12 August 2013.

67. Ringquist EJ, Kostadinova T. Assessing the effectiveness of international environmental agreements: The case of the 1985 Helsinki Protocol. American Journal of Political Science. 2005;49(1):86-102.

68. von Stein J. The international law and politics of climate change. Ratification of the United Nations Framework Convention and the Kyoto Protocol. Journal of Conflict Resolution. 2008;52(2):243-268.

69. Finus M, Tjøtta S. The Oslo Protocol on sulfur reduction: The great leap forward? Journal of Public Economics. 2003;87(9-10):2031-2048. 